\title{
O tema mudanças climáticas em teses e dissertações brasileiras de educação ambiental
}

Danielle Aparecida Reis Leite danielle.reis@uftm.edu.br orcid.org/0000-0002-6314-0364 Universidade Federal do Triângulo Mineiro (UFTM), Uberaba, Minas Gerais, Brasil

Luciano Fernandes Silva lufesilv@gmail.com orcid.org/0000-0003-2041-3809 Universidade Federal de ltajubá (UNIFEI). Itajubá, Minas Gerais, Brasil

\section{RESUMO}

Este trabalho objetivou identificar aspectos do tema mudanças climáticas destacados em teses e dissertações do campo de pesquisa em Educação Ambiental (EA). Através da análise dessas informações, procurou-se explorar as compreensões apresentadas nessas pesquisas sobre o referido tema. O corpus documental, composto por dezessete dissertações de EA que exploram o tema mudanças climáticas, defendidas no período de 1987 a 2010, foi elaborado através do Banco de Teses e Dissertações da CAPES. A partir de alguns critérios, foram escolhidas cinco pesquisas desse conjunto cujos textos completos foram submetidos à análise de conteúdo. Das considerações a respeito do tema, presentes nessas pesquisas, foram elaboradas três categorias que apresentam as compreensões dos autores desses trabalhos sobre as causas das mudanças climáticas, suas consequências e as possíveis medidas capazes de mitigar seus efeitos. Ao discutir as origens do fenômeno, dois trabalhos recorrem a sua complexidade para justificar a dificuldade de eleger uma única causa, seja ela de origem natural ou antrópica e, assim, evidenciam as controvérsias científicas envolvidas nesse assunto. Três pesquisas apresentam posicionamentos sensacionalistas ao destacar as consequências das mudanças climáticas, aspecto que é problematizado por outros dois trabalhos ao enfatizarem que as incertezas relacionadas a um fenômeno complexo dificultam a apresentação de tais previsões. Por fim, é importante enfatizar os argumentos presentes em uma dissertação que, ao apresentar as medidas de mitigação para o fenômeno, trata das controvérsias econômicas e políticas e que resultam do debate acerca da adoção de tais medidas. Com isso, conclui-se que esses pesquisadores apresentam informações importantes sobre o tema, aspecto que, certamente, pode incentivar a área de pesquisa em EA a aprofundar as reflexões sobre as mudanças climáticas e a propor novos problemas de pesquisa.

PALAVRAS-CHAVE: Mudanças Climáticas. Educação Ambiental. Controvérsia. 


\section{INTRODUÇÃO}

$\mathrm{Na}$ atualidade, as discussões sobre as mudanças climáticas são amplamente divulgadas, e diversas questões referentes ao tema estão diariamente presentes em nossas vidas, sobretudo através dos meios de comunicação. $O$ assunto é centro de debates que versam sobre as origens e os efeitos do fenômeno e as diferentes maneiras de amenizar seus impactos na sociedade e no ambiente. Entretanto, as informações divulgadas retratam, geralmente, a existência de um consenso, principalmente dentre a comunidade científica, de que as mudanças climáticas têm origem na ação antrópica sobre a Natureza. A Revolução Industrial é apresentada como marco inicial da era das mudanças climáticas, ao se considerar que existe uma relação entre o aumento na concentração de gás carbônico na atmosfera e a elevação da chamada temperatura média do planeta.

No entanto, diferente das concepções sensacionalistas, e longe de qualquer consenso, considerações discursivas sobre as mudanças climáticas estão frequentemente associadas com controvérsias de diferentes naturezas. Por envolver valores, conveniências pessoais, pressões sociais e econômicas e aspectos de natureza ética e religiosa, um tema controverso é responsável por gerar posicionamentos diversificados que não conduzem a conclusões simples (REIS, 2009).

Na ciência, por exemplo, questiona-se se a elevação da temperatura média do planeta se deve, única e exclusivamente, à ação antrópica no meio ambiente. No campo econômico e político, a avaliação dos impactos financeiros causados pela implementação de medidas mitigativas ao controle do fenômeno gera uma série de divergências entre líderes políticos (REIS; SILVA; FIGUEIREDO, 2015).

Além da natureza controversa desse tema ambiental, destacamos, ainda, a complexidade desse fenômeno climático. A complexidade é característica de um sistema constituído por componentes heterogêneos e inseparavelmente associados, cuja interação gera acontecimentos permeados pelo acaso. A interdependência entre os elementos que constituem o sistema complexo faz com que pequenas modificações em um dos seus constituintes gerem grandes modificações no todo (MORIN, 2007).

O clima é um sistema complexo, composto por subsistemas heterogêneos que, apesar de possuírem comportamentos particulares e serem caracterizados por propriedades físicas e químicas específicas, interagem constantemente e geram produtos capazes de alterar a configuração inicial. Esse sistema complexo possui algumas características intrínsecas, tais como o não determinismo, a incerteza, a instabilidade, a probabilidade e a irreversibilidade (PRIGOGINE, 2002). Do ponto de vista científico, essas características sugerem que o clima sofre influência da disposição geográfica dos continentes, oceanos e geleiras, ecossistemas terrestres, constituintes atmosféricos, força gravitacional e rotação terrestre, radiação solar etc. Ao mesmo tempo, o sistema climático também sofre influências de outros sistemas, como as organizações sociais, guiadas por interesses políticos e econômicos (REIS; SILVA; FIGUEIREDO, 2015; WATANABECARAMELLO, 2012).

De modo particular, consideramos que as controvérsias desse tema estão intrinsecamente relacionadas com a sua complexidade. De fato, conforme pontuado por Morin (2007, p. 69), compreender a realidade através de um 
pensamento complexo significa entender "que jamais poderemos escapar da incerteza e que jamais poderemos ter um saber total apresentando, assim, maneiras diversificadas de se compreender a realidade". Com isso, o autor destaca que em uma realidade complexa, as contradições e os dissensos não podem ser evitados, ou seja, a complexidade possibilita o surgimento das controvérsias. Ainda de acordo com o filósofo, "quando se chega por vias empírico-racionais as contradições, isso não significa um erro, mas o atingir de uma camada profunda da realidade que, justamente por ser profunda não encontra tradução em nossa lógica" (p. 68).

Através desse raciocínio, Reis, Silva e Figueiredo (2015) destacam que analisar os fenômenos climáticos significa lidar com possibilidades, o que, por sua vez, contribui para o surgimento de dissensos associados não apenas à perspectiva da ciência, mas, também, do ponto de vista de aspectos sociais, econômicos e políticos.

Nesse sentido, concordamos que a população deve ter conhecimento das contradições que acompanham os debates em torno das questões socioambientais, uma oportunidade para aprofundar as discussões e esclarecer essas diferentes interpretações (CARVALHO, 1989). Para Jacobi e colaboradores (2011), o conhecimento dessas contradições relacionadas ao tema mudanças climáticas poderá evitar a propagação de representações fatalistas e apocalípticas, geralmente associadas à ideia de que nada pode ser feito para enfrentar as consequências catastróficas do fenômeno para a humanidade.

Conhecendo essas características intrínsecas às mudanças climáticas, fomos motivados a entender as discussões mobilizadas pelo campo da Educação Ambiental (EA) sobre o fenômeno. Ou seja, propomos a realização de uma investigação com o intuito de identificar e analisar compreensões elaboradas pelo campo de pesquisa em EA sobre o tema em questão.

Para uma investigação dessa natureza, a pesquisa documental se mostrou como a mais indicada. Nesse contexto, compreendemos que a análise dessa produção teórica possibilitaria a sistematização e a valorização do conhecimento já produzido pelo campo da pesquisa em EA sobre o tema mudanças climáticas. Para tanto, optamos pela análise de dissertações e teses brasileiras de Educação Ambiental que tratam do fenômeno mudanças climáticas, opção que também pode ser justificada pela baixa circulação desse tipo de trabalho e pela falta de incentivo à sua divulgação (FRACALANZA et al., 2008).

Cabe mencionar, ainda, que a opção pela análise de teses e dissertações também se justifica pela articulação deste trabalho ao Projeto de Pesquisa $\mathrm{A}$ Educação Ambiental no Brasil: análise da produção acadêmica (dissertações e teses) (CARVALHO et al., 2016). Esse projeto possui o objetivo de mapear a produção das teses e dissertações brasileiras de EA e desenvolver estudos do tipo estado da arte a partir de diferentes focos e abordagens (vide: www.earte.net).

Nesse sentido, esta pesquisa buscou responder à seguinte questão: que aspectos das mudanças climáticas são destacados em teses e dissertações de EA em que essa temática é central? O que essas informações revelam acerca das compreensões elaboradas nesses trabalhos sobre o referido fenômeno?

Assim, o objetivo desta pesquisa foi o de identificar os aspectos do tema mudanças climáticas, destacados em teses e dissertações de EA, e através da 
análise dessas informações, explorar as compreensões apresentadas nessas pesquisas sobre o referido tema.

Dado o problema e o objetivo da pesquisa, na continuidade apresentamos os procedimentos utilizados para a construção do corpus documental e os métodos empregados para a análise dos dados.

\section{PROCEDIMENTOS DE PESQUISA}

Esta é uma investigação de natureza qualitativa do tipo estado da arte, ou seja, uma pesquisa de caráter bibliográfico que visa "mapear e discutir uma certa produção acadêmica em diferentes campos do conhecimento, tentando responder que aspectos e dimensões que vêm sendo destacados e privilegiados em diferentes épocas e lugares" (FERREIRA, 2002, p. 257).

Considerando o objetivo deste trabalho, determinamos que o corpus documental fosse constituído por teses e dissertações de EA defendidas no Brasil até 2010 (ano anterior ao início desta investigação) e que abordassem o tema mudanças climáticas, de maneira central, na investigação. Para a seleção desses trabalhos, utilizamos o Banco de Teses e Dissertações da CAPES, obedecendo às seguintes etapas:

a) No campo de busca do referido banco, utilizamos as palavras-chave: mudanças climáticas e educação ambiental; aquecimento global e educação ambiental; efeito estufa e educação ambiental, e selecionamos a opção de busca por todas as palavras. Assim, resgatamos 45 dissertações de mestrado e duas teses de doutorado;

b) Posteriormente, realizamos a leitura e análise do título, resumo e palavraschave desses 47 trabalhos a fim de selecionar as pesquisas de EA que fizessem referências ao tema mudanças climáticas. Nesse momento, selecionamos 22 dissertações de mestrado que foram classificadas em três grupos: (i) treze eram de EA e abordavam, explicitamente, o tema mudanças climáticas; (ii) três eram de EA, mas deixavam dúvidas ao enfoque dado para as mudanças climáticas; (ii) seis exploravam as mudanças climáticas, mas deixavam dúvidas se eram de EA (utilizamos os critérios determinados pelo projeto EArte para classificação desses trabalhos, disponíveis para consulta em: http://www.earte.net/?page=criterios-selecao).

c) Por fim, para a resolução das dúvidas referentes aos trabalhos agrupados em (ii) e (iii), realizamos a busca e a leitura integral dessas 22 pesquisas de mestrado e concluímos que, até o ano de 2010, foram produzidas dezessete dissertações de EA que abordam o tema mudanças climáticas, de maneira central, em seus propósitos de investigação.

Para a análise dos trabalhos completos, selecionamos cinco dissertações defendidas entre os anos de 2003 a 2010. Optamos por esta delimitação, uma vez que essas dissertações apresentam reflexões aprofundadas do tema, oferecendo as informações importantes para alcançarmos o objetivo do trabalho. O Quadro 1 apresenta as principais informações para a caracterização desses trabalhos. 
Quadro 1 - Informações referentes às dissertações que foram submetidas à análise do texto completo

\begin{tabular}{|c|r|r|c|}
\hline Ano & Título & Autor & Código \\
\hline 2003 & $\begin{array}{r}\text { A Física na Educação Ambiental: A Questão do } \\
\text { Efeito Estufa }\end{array}$ & SANTOS, L. C. A. & T1 \\
\hline 2007 & $\begin{array}{c}\text { Educação, jornalismo e meio ambiente: leituras } \\
\text { sobre a crise ecológica no contexto do } \\
\text { aquecimento global }\end{array}$ & LÜCKMAN, A. P. & T2 \\
\hline 2008 & $\begin{array}{r}\text { A ética no discurso do Jornal Zero Hora sobre as } \\
\text { mudanças climáticas }\end{array}$ & TEIXEIRA, D. V. & T3 \\
\hline $\begin{array}{r}\text { A inconveniência de uma verdade: } \\
\text { representações sociais de estudantes } \\
\text { universitários sobre o aquecimento global }\end{array}$ & FERREIRA, A. T. & T4 \\
\hline $\begin{array}{c}\text { O debate sobre o aquecimento global em sala } \\
\text { de aula: o sujeito dialógico e a responsabilidade } \\
\text { do ato frente a um problema sociocientífico } \\
\text { controverso }\end{array}$ & BARBOSA, L. G. & T5 \\
\hline
\end{tabular}

Fonte: Autoria própria (2020).

Para sistematizar os dados, elaboramos fichas de leitura para registrarmos os excertos dos textos que respondiam às indagações desta pesquisa. Para a análise desse material, nos inspiramos na Análise de Conteúdo (BARDIN, 2009), com a realização da análise temática e a elaboração de categorias a posteriori.

No próximo item, apresentamos as principais características das dezessete dissertações de EA, defendidas entre 1987 e 2010, cujo tema central de pesquisa é o das mudanças climáticas. Além disso, também exploramos os principais objetivos e resultados das cinco dissertações selecionadas para a análise dos textos completos.

\section{PRINCIPAIS CARACTERÍSTICAS DAS DISSERTAÇÕES DE EDUCAÇÃO AMBIENTAL QUE TRATAM DO TEMA MUDANÇAS CLIMÁTICAS}

A Figura 1 apresenta um gráfico que sistematiza a distribuição temporal dos trabalhos que constituem o corpus documental. Constatamos que a primeira dissertação de EA que explora as mudanças climáticas foi defendida em 1994, e que há uma maior concentração de pesquisas a partir de 2008.

Figura 1 - Produção acadêmica por ano de conclusão

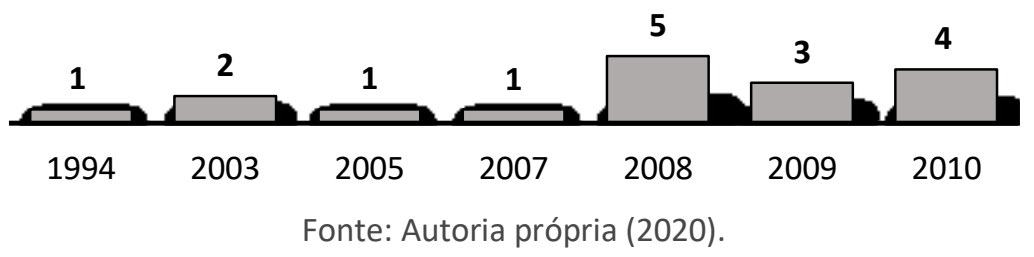

No início do século XXI, o tema mudanças climáticas passou a ser divulgado, de maneira expressiva, pela mídia, chamando a atenção da população para esse assunto. Em 2006, por exemplo, foi lançado o documentário Uma Verdade Inconveniente que, com apelo sensacionalista, apresenta dados impactantes do fenômeno. Além disso, em 2007, foi divulgado o quarto relatório do Painel 
Intergovernamental sobre Mudanças Climáticas (IPCC), cujos dados também impressionam a sociedade. Assim, entendemos que esses acontecimentos podem ter influenciado a elevação na quantidade de pesquisas sobre as mudanças climáticas no campo da EA a partir de 2008.

Outro dado relevante é que essas pesquisas foram produzidas em Instituições de Ensino Superior (IES) localizadas nas regiões Sudeste, Sul e Centro-Oeste, nos estados de São Paulo (quatro trabalhos), Rio Grande do Sul (quatro trabalhos), Rio de Janeiro (três trabalhos), Paraná (dois trabalhos), Santa Catarina (dois trabalhos), Minas Gerais (um trabalho) e Mato Grosso (um trabalho). A distribuição territorial desigual da produção acadêmica de EA no Brasil está vinculada ao fato de a maior parte dos programas de pós-graduação ser oferecida por instituições localizadas nas regiões sul e sudeste do país (FRACALANZA et al., 2008).

Outro dado importante é o da natureza administrativa das instituições de proveniência dessas pesquisas: oito procedem de instituições federais, um de instituição estadual, sete de instituições privadas e um de instituição comunitária. Chama a atenção o fato de praticamente metade de número de trabalhos selecionados serem provenientes de IES particulares, uma vez que é frequente a constatação da contribuição mais acentuada de instituições públicas para a pesquisa em EA (FRACALANZA et al., 2008; RINK, 2014; CARVALHO; CAVALARI; SILVA, 2015).

Também é relevante destacar a ausência de teses de doutorado, já que quinze pesquisas são de mestrado acadêmico (MA) e duas de mestrado profissionalizante (MP). Investigações semelhantes destacam a parcela reduzida de teses brasileiras de EA, uma vez que o número de cursos de doutorado é inferior aos de mestrado (FRACALANZA et al., 2008; RINK, 2014; CARVALHO; CAVALARI; SILVA, 2015).

Por fim, apresentamos que os Programas de Pós-Graduação aos quais esses trabalhos estão vinculados são, em sua maioria, de duas áreas específicas da CAPES: Educação (área 38) e Ensino (área 46).

O Quadro 2 sistematiza as informações anteriormente apresentadas.

Quadro 2 - Informações das Instituições e dos Programas de Pós-Graduação das dissertações de EA que tratam do tema mudanças climáticas

Natureza

\begin{tabular}{|c|c|c|c|c|}
\hline Instituição & $\begin{array}{c}\text { Natureza } \\
\text { administrativa }\end{array}$ & Programa de Pós-Graduação & $\begin{array}{l}\text { Grau de } \\
\text { titulação }\end{array}$ & Número \\
\hline FURG & Federal & Educação Ambiental & MA & 2 \\
\hline UFSC & Federal & Educação & MA & 1 \\
\hline UFMG & Federal & Educação & MA & 1 \\
\hline UFRJ & Federal & Educação & MA & 1 \\
\hline UFTPR & Federal & $\begin{array}{c}\text { Ensino de Ciência e } \\
\text { Tecnologia }\end{array}$ & MP & 1 \\
\hline USP & Estadual & Ensino de Ciências & MA & 1 \\
\hline UFMT & Federal & Física Ambiental & MA & 1 \\
\hline ENCE & Federal & $\begin{array}{c}\text { Estudos Populacionais e } \\
\text { Pesquisas Sociais }\end{array}$ & MA & 1 \\
\hline MACKENZIE & Privada & $\begin{array}{c}\text { Educação, Arte e História da } \\
\text { Cultura }\end{array}$ & MA & 2 \\
\hline
\end{tabular}




\begin{tabular}{|c|c|c|c|c|}
\hline PUC-RS & Privada & $\begin{array}{c}\text { Educação em Ciências e } \\
\text { Matemática }\end{array}$ & MA & 1 \\
\hline PUC-PR & Privada & Educação & MA & 1 \\
\hline UNOESC & Comunitária & Educação & MA & 1 \\
\hline UNIMEP & Privada & Educação & MA & 1 \\
\hline USM & Privada & $\begin{array}{c}\text { Educação, Administração e } \\
\text { Comunicação }\end{array}$ & 1 \\
\hline UNIPLI & Privada & $\begin{array}{c}\text { Ensino de Ciências da Saúde e } \\
\text { do Meio Ambiente }\end{array}$ & MP & 1 \\
\hline
\end{tabular}

Fonte: Autoria própria (2020).

Tendo apresentado as informações que caracterizam as dezessete dissertações de EA que tratam do tema mudanças climáticas, defendidas no Brasil até o ano de 2010 e selecionadas no Banco de Teses e Dissertações da CAPES, consideramos relevante destacar os objetivos e as abordagens conferidas ao tema mudanças climáticas pelas cinco dissertações submetidas à análise apresentada neste artigo.

Na dissertação $T 1$, a autora analisa as representações de alunos de ensino médio e de um curso de Licenciatura em Física sobre o meio ambiente. O objetivo principal foi o de apresentar as contribuições da Física para a compreensão da questão ambiental, com o intuito de destacar o papel dessa área do conhecimento para a EA. Com isso, a autora delineia os conhecimentos físicos sobre o efeito estufa, um tema ambiental de relevância social ao qual se associa o aquecimento global e as mudanças climáticas. Com uma percepção ampliada sobre o fenômeno, a autora o caracteriza como um tema complexo e dinâmico, ao qual estão associadas uma série de controvérsias científicas.

Considerando que o jornalismo possui um caráter educativo que pode contribuir para a sensibilização da sociedade sobre a crise ambiental, a autora da dissertação $\mathrm{T} 2$ analisou como as notícias sobre meio ambiente são recebidas pelo público. Para o levantamento dos dados, a pesquisadora organizou grupos constituídos por estudantes de diferentes cursos de graduação de uma universidade federal, que analisaram e discutiram dois textos de jornal e um texto de revista que abordam a temática do aquecimento global. A autora construiu uma síntese da situação climática do planeta através dos dados presentes em relatórios provenientes de diferentes conferências internacionais sobre as mudanças climáticas. De maneira específica, a pesquisadora apresenta as causas antrópicas do fenômeno, explora algumas das suas consequências para a sociedade e identifica medidas que possam frear o avanço do fenômeno.

Reconhecendo as contribuições do jornalismo para a formação de opinião e evidenciando a emergência do debate em torno das mudanças climáticas no contexto social, a autora da dissertação T3 visou compreender o processo de construção do discurso ético sobre o referido fenômeno no jornal Zero Hora. Para tanto, a pesquisadora analisou três reportagens sobre as mudanças climáticas publicadas pelo referido jornal. A pesquisadora detalha os resultados dos relatórios do IPCC para explorar as causas e as consequências do fenômeno. Considerado como um fenômeno de origem antrópica, a autora associa as causas das mudanças climáticas ao capitalismo, uma vez que este incentiva o consumismo e a exploração inconsequente do meio ambiente. 
A dissertação T4 apresenta os resultados de um estudo sobre as representações de estudantes de um curso de graduação em Comunicação Social sobre o tema aquecimento global. Para o autor desse trabalho, o aquecimento global de origem antrópica é o responsável por ocasionar diversas alterações no clima, o que justifica a emergência do debate sobre o assunto. Em um discurso ampliado sobre o fenômeno, o autor explora as dimensões científicas, políticas, econômicas, sociais do tema, evidenciando a complexidade das discussões internacionais acerca das formas para conter o seu avanço e minimizar suas consequências.

Na dissertação T5, o autor analisa três episódios de duas aulas de Química ministradas em uma escola pública - que envolveram um conjunto de atividades didáticas relacionadas ao aquecimento global. A justificativa para a seleção desse tema para a sequência de atividades está relacionada com a repercussão do fenômeno que, frequentemente, é apresentado através de um apelo sensacionalista e catastrofista. Para o pesquisador, "esta realidade demanda da escola pautar a discussão formal das controvérsias em torno ao fenômeno, fomentando nos estudantes a capacidade de avaliar argumentos e se posicionar enquanto participantes dos debates contemporâneos" (T5, 2010, p. 35). Com isso, o autor apresenta o aquecimento global como um problema sociocientífico controverso e analisa distintos posicionamentos científicos no debate associado às causas do fenômeno.

Tendo em mente essas informações, o próximo item apresenta o resultado da análise dessas dissertações e indica algumas compreensões a respeito do tema mudanças climáticas identificadas nesses trabalhos.

\section{COMPREENSÕES DO TEMA MUDANÇAS CLIMÁTICAS APRESENTADAS EM DISSERTAÇÕES DE EDUCAÇÃO AMBIENTAL}

Com a análise das dissertações selecionadas, identificamos algumas características do fenômeno mudanças climáticas destacadas pelo campo de pesquisa da EA, agrupadas em seis categorias de análise, das quais iremos explorar três, denominadas: Causas, Consequências e Medidas de Mitigação.

Constatamos que, ao discutirem as causas das mudanças climáticas, os autores das dissertações T2, T3 e T4 indicam que o fenômeno tem origem na ação do ser humano sobre a natureza. A autora da dissertação T2 caracteriza as mudanças climáticas como "um trágico fenômeno que, de acordo com os estudos científicos, tem no consumismo dos humanos uma de suas principais origens" (T2, 2007 , p. 12) e enfatiza que o IPCC "considera com $90 \%$ de certeza que as ações humanas contribuem para as mudanças climáticas do planeta" (T2, 2007, p. 42).

O autor da dissertação T3 destaca:

A crise que hoje se vivencia, gerada pelo atual modelo capitalista de sociedade, com sua ganância, extrapolou todas as formas de vida, até provocar as mudanças do clima que, por sua vez, geraram exclusão social, fome, doenças e desequilíbrio da natureza, entre outros problemas (T3, 2008, p. 93). 
Por fim, o autor da dissertação T4, enfatiza que "a maioria das comunidades científicas do mundo julga que o aquecimento global é causado pela ação humana que leva à elevação do nível de concentração de poluentes na atmosfera" (T4, 2009, p. 15) e, em outra passagem, destaca que:

[...] As ações antropogênicas, como a queima de combustíveis fósseis, o desmatamento, o avanço da agropecuária, e a emissão de gases poluentes provenientes das atividades industriais são as principais causas das mudanças climáticas globais (T4, 2009, p. 49).

Certamente, posicionamentos desse tipo nos incentivam a repensar a relação que estamos estabelecendo com a natureza. O ser humano é parte do sistema climático e, por isso, suas ações trazem impactos para o meio ambiente que não devem ser ignorados. Entretanto, as considerações dos autores dessas duas dissertações traduzem uma linearidade entre causa (atividade antrópica) e efeito (mudanças climáticas), que pode ser questionada quando consideramos a complexidade do fenômeno e as incertezas relacionadas ao sistema climático.

Além disso, ao afirmarem que a comunidade científica está certa de que o ser humano é o único responsável pela ocorrência do fenômeno, esses pesquisadores anulam as controvérsias científicas associadas ao peso das atividades antrópicas para as mudanças no clima. Em outras palavras, podemos dizer que não há dúvidas de que o ser humano seja um dos principais causadores das mudanças climáticas atuais. Mas, ao mesmo tempo, o fenômeno deve ser discutido por meio de uma visão complexa, que nos aproxime, mesmo de um ponto de vista epistemológico, um pouco mais da complexidade do problema que lidamos. Por isso, consideramos que o posicionamento da autora da dissertação T1 soa como mais adequado ao pontuar que:

Estamos, com certeza, lançando na atmosfera gases-estufa e outros, resultantes de alguma atividade antropogênica. Que eles podem contribuir para o aumento da temperatura terrestre, devido à absorção dos gases estufa, é uma hipótese viável. Porém, se isso está efetivamente contribuindo, e de quanto é essa contribuição, ainda são questões em aberto (T1, 2003, p. 53).

Para justificar essa afirmação, a autora da dissertação T1 destaca que o "nosso planeta é um sistema complexo e dinâmico. Os domínios orgânicos, gasosos, líquidos e sólidos da Terra são intimamente interligados. Uma mudança em uma das partes do sistema provavelmente afetará outras partes" (T1, 2003, p. 36). Concordamos que o sistema climático é complexo, sendo constituído por diversos sistemas heterogêneos, caracterizados por suas composições químicas e por propriedades físicas particulares que, embora apresentem comportamentos próprios, interagem e agregam novas estruturas capazes de gerar mudanças significativas no clima (WATANABE-CARAMELLO, 2012; REIS; SILVA; FIGUEIREDO, 2015). Nesse contexto, é relevante considerar que a sociedade é uma dentre outras tantas organizações sistêmicas que interferem no curso das mudanças climáticas. Conforme destacado pela autora do trabalho T1: reequilibrar o sistema com as transformações realizadas por nós, uma vez que conseguimos modificar o ambiente em curtos espaços de tempo (T1, 2003, p. 53). 
Apresentando considerações mais próximas desse posicionamento, as dissertações T1 e T5 revelam que as causas das mudanças no clima podem ter origens naturais e antrópicas. Os autores desses trabalhos indicam o caráter natural do fenômeno, sem descartar a possibilidade de que esteja sendo intensificado pela ação humana.

Esses pesquisadores destacam que o estudo da história geológica da Terra evidencia variações da temperatura relacionadas às alterações climáticas em diferentes momentos históricos, indicando que não se trata de um fenômeno recente, que teve sua origem após a Revolução Industrial. Além disso, os autores desses trabalhos concordam que a análise do balanço energético da Terra oferece elementos que corroboram a tese de que este fenômeno possui origens naturais e que pode ser intensificado por atividades antrópicas. De acordo com o autor da dissertação T5:

Conhecemos três formas fundamentais de alterar o balanço energético da Terra, de modo a repercutir na alteração da sua temperatura média, e consequentemente em outros parâmetros do clima: (1) variar a energia solar incidente por alterações no Sol ou na órbita da Terra; (2) variar a fração da radiação refletida (albedo) por mudanças na cobertura das nuvens, na concentração de aerossóis atmosféricos ou na coloração da cobertura dos solos, etc; (3) variar a radiação infravermelha retida pela atmosfera terrestre pela variação de sua concentração de gases-estufa (T5, 2010, p. 35).

Conforme explorado por Reis, Silva e Figueiredo (2015), a análise do sistema terrestre permite a identificação de fenômenos naturais que alteram a radiação absorvida e refletida pelo planeta, o que influencia as variações das temperaturas superficiais e provoca interferência nos fenômenos climáticos. Ao mesmo tempo, esses pesquisadores destacam que a complexidade do fenômeno dificulta elencar as principais causas ou quais trazem maiores impactos, o que, segundo os pesquisadores, contribui para o surgimento de algumas controvérsias científicas a respeito das origens desse fenômeno.

Os autores das dissertações T1 e T5 reconhecem a existência de controvérsias científicas associadas às causas das mudanças climáticas. Na pesquisa $T 5$, por exemplo, o pesquisador ressalta que a produção do conhecimento científico é realizada por uma comunidade polissêmica e, por isso, identifica diferentes "vozes presentes em alguns dos vários discursos que perpassam as controvérsias sobre a ocorrência e as causas do aquecimento global" (T5, 2010, p. 32).

No campo científico, algumas controvérsias associadas ao fenômeno das mudanças climáticas têm origem nas discussões relacionadas com suas causas. Uma parte da comunidade científica questiona a existência de um aquecimento global, outros problematizam a tese de que as emissões de gases estufa causem um impacto no clima mais significativo do que os fenômenos naturais, enquanto outros grupos compreendem que a ação antrópica no meio ambiente seja a principal causa das mudanças climáticas (VEIGA; VALE, 2007; WATANABECARAMELLO, 2012; REIS; SILVA; FIGUEIREDO, 2015).

Em relação às consequências das mudanças climáticas, na análise dos textos completos das dissertações selecionadas, identificamos posicionamentos que evidenciam a elevação das temperaturas superficiais terrestres, desertificação, derretimento das geleiras, elevação do nível dos oceanos, maior incidência de 
tempestades e furacões, dentre outros efeitos do fenômeno apresentados pelos trabalhos T2, T3 e T4.

Todavia, o que chama a atenção é a construção de um discurso assertivo, catastrófico e sensacionalista ao tratar dessas consequências. A autora da dissertação T2 enfatiza que "um efeito estufa intenso poderá 'derreter' grandes quantidades de gelo das regiões polares, provocando uma inundação em toda a Terra" (T2, 2007, p. 43). Na dissertação T3, a pesquisadora destaca que "as mudanças nos padrões de vento e precipitação, associadas ao derretimento das geleiras, devem trazer o desaparecimento do continente Ártico antes do final do século" (T3, 2008, p. 48). Por fim, apresentamos o posicionamento do autor do trabalho T4 ao destacar que: "Já é certo que o aquecimento global médio ultrapassará $1^{\circ} \mathrm{C}$ por volta de 2050 e talvez chegue a $6^{\circ} \mathrm{C}$ até o fim do século" (T4, 2009, p. 55).

Concordamos com Jacobi et al. (2011, p. 136) sobre a necessidade de reconhecer os "efeitos e vulnerabilidades a que todos estamos expostos diante das mudanças climáticas globais". Por isso, entendemos que as previsões acerca das consequências das mudanças climáticas devem ser divulgadas para a sociedade, uma vez que nos estimulam a refletir a respeito da relação que estabelecemos com o meio ambiente, além de incentivarem a mobilização da população junto aos governantes para a implementação de medidas que minimizem a degradação ambiental.

Por outro lado, as previsões sensacionalistas reduzem o sistema climático a acontecimentos catastróficos e previsíveis, anulando a complexidade do fenômeno. Por isso, seria pertinente que o campo de pesquisa em EA problematizasse as incertezas associadas aos possíveis impactos das mudanças climáticas para a sociedade, principalmente por estarmos lidando com previsões, passíveis de dúvidas e incertezas.

Por constituir um sistema aberto, o clima está sujeito à interferência de variáveis cuja interação pode resultar em consequências diversificadas. Com isso, destacamos o posicionamento da autora da dissertação T1 ao afirmar que "no atual estado da pesquisa sobre as mudanças climáticas, fazer previsões é muito difícil. Mas podemos obter indícios sobre as possibilidades futuras" (T1, 2003, p. 48). Uma das características associadas aos fenômenos complexos é, justamente, o distanciamento das certezas a respeito do futuro desse sistema. Caos, flutuações e imprevisibilidade são suas principais características, visto que a interação entre as variáveis desse sistema pode encarregar-se de conduzi-lo a um estado que antes não fora previsto.

Esse também é o posicionamento de outros pesquisadores, como Kerr (2012, p. 10), ao indicar que "essas tendências [climáticas] estão indicadas como bastante prováveis, mas não são certezas absolutas”. Watanabe-Caramello (2012, p. 215) complementa essa consideração, enfatizando que não podemos elencar com qualquer grau de certeza quais serão as principais consequências do fenômeno e, tampouco, se as medidas de mitigação propostas, de fato, alcançarão sucesso em deter as mudanças no clima, já que "os sistemas sofrem influências incontáveis e de naturezas distintas, de modo que não será possível prever com exatidão como o planeta deverá estar daqui algumas dezenas de anos". 
Cabe enfatizarmos que, quando problematizamos as previsões das consequências das mudanças climáticas, nossa intenção não é a de eximir nossa responsabilidade, enquanto sociedade, com o meio ambiente. Embora não possamos ter certeza das implicações das alterações climáticas e dos seus efeitos, não é plausível afirmarmos que elas não se concretizarão, visto que convivemos com o risco. Com isso, destacamos que as medidas preventivas são necessárias e importantes (OLIVEIRA; VECCHIA, 2009).

As previsões relacionadas aos possíveis efeitos das mudanças climáticas incentivam a proposição de medidas de mitigação para conter o avanço dessas consequências indesejadas. Nas cinco dissertações analisadas, são apresentadas algumas ações como, por exemplo, a redução na emissão de combustíveis fósseis, a utilização de fontes alternativas de energia e o sequestro de carbono. De acordo com a autora da dissertação T1, "essas medidas devem ser tomadas por conta da incerteza do conhecimento dos impactos que a atividade antropogênica pode causar" (T1, 2003, p. 53).

Embora essas dissertações não esclareçam, entendemos que ao tratar das medidas de mitigação é relevante considerar e enfatizar uma das características dos sistemas complexos: a irreversibilidade (PRIGOGINE, 2002). De acordo com Reis, Silva e Figueiredo (2015, p. 545), os "fenômenos climáticos podem ser descritos como uma sucessão de fenômenos não reversíveis, o que provoca o aumento da entropia do planeta, evoluindo sempre em um único sentido". Mesmo que as emissões de combustíveis fósseis fossem reduzidas drasticamente, por exemplo, não é possível afirmar que a atmosfera regressaria ao comportamento anterior ao do acúmulo desses gases (WATANABE-CARAMELLO, 2012; REIS; SILVA; FIGUEIREDO, 2015), ou seja, mais um argumento capaz de incentivar a adoção das medidas para a contenção dos efeitos desse fenômeno.

Quando trata das medidas de mitigação, o autor da dissertação T4 destaca a relação do assunto com aspectos políticos, econômicos e sociais, evidenciando o surgimento de controvérsias relacionadas à adesão dessas medidas por diferentes países. Como nos apresenta Lima (2009, p. 5), há no contexto das mudanças climáticas:

[...] um conjunto de elementos sociais, político-ideológicos, econômicos, tecnológicos e culturais que definem sua complexidade e devem, portanto, ser incluídos no esforço de sua compreensão para evitar conclusões reducionistas e tentativas de solução monodimensionais.

Assim, esse pesquisador destaca que a implementação de medidas de mitigação amplas e eficientes esbarra no desafio de estabelecer um consenso mínimo entre as nações mais influentes e poderosas do mundo. Nesse sentido, revela que as intenções políticas, econômicas e sociais interferem na tomada de decisão relacionada com a intenção de aderir ou não às medidas de mitigação. Uma vez que as medidas propostas podem acarretar sérios impactos econômicos, essa pesquisa explora as controvérsias associadas às negociações políticas de diferentes países na adesão dessas propostas que visam conter as mudanças no clima de origem antrópica.

O principal argumento gira em torno dos impactos financeiros causados pela redução da emissão de combustíveis fósseis pelo setor industrial. O desafio de aderir à redução da emissão dos gases responsáveis pela intensificação do efeito 
estufa implica em um investimento econômico que muitos países não estão dispostos a assumir, já que os envolvidos nessa negociação preocupam-se, majoritariamente, com o capital produzido pelas indústrias. Ao problematizar as implicações do Protocolo de Kyoto para a economia mundial, o autor da dissertação T4 esclarece:

A maior dificuldade para a implementação do Protocolo é de ordem econômica. Os principais países poluidores como os Estados Unidos e o Japão continuam emitindo mais $\mathrm{CO}_{2}$ e teriam de alterar significativamente sua economia para atingirem as metas acordadas em Kyoto. Os Estados Unidos recusaram a ratificar o documento, alegando que suas economias seriam prejudicadas se o fizessem (T4, 2009, p. 43).

Desse modo, esse cenário também é responsável por acarretar diversas controvérsias políticas, já que implica em negociações relacionadas ao controle das emissões dos combustíveis fósseis. Em outras palavras podemos dizer que "O desafio da cooperação internacional envolve decisões políticas de grande peso, pois cada país tem interesses dos mais diferenciados no combate à mudança climática" (VEIGA; VALE, 2007, p. 17).

\section{CONSIDERAÇÕES FINAIS}

Com esta investigação objetivamos explorar as compreensões sobre o tema mudanças climáticas elaboradas pela produção teórica em EA, representada por dissertações e teses. Em um corpus documental constituído por dezessete dissertações de EA, selecionamos cinco pesquisas que foram submetidas à análise dos textos completos, quando identificamos uma série de informações relacionadas com causas, consequências e medidas de mitigação que revelam as compreensões dos autores desses trabalhos sobre o fenômeno.

Desse conjunto, entendemos que três pesquisas (T2, T3 e T4) descrevem as mudanças climáticas com um posicionamento muito próximo daquele presente nos meios de comunicação em massa. Apesar de apresentarem dados subsidiados por fontes científicas, como os relatórios do IPCC, por exemplo, esses pesquisadores exploram o fenômeno através de uma postura determinista e sensacionalista. Todavia, não desconsideramos que essas pesquisas apresentam críticas pertinentes à relação que o ser humano tem estabelecido com o meio ambiente, evidenciando elementos que colocam em xeque o modelo de produção capitalista. Além disso, as controvérsias políticas e econômicas são evidenciadas pelo autor da dissertação T4 quando explora o debate e a oposição de diferentes nações na adesão de medidas que visam reduzir a emissão de combustíveis fósseis.

Por outro lado, as outras duas investigações (T1 e T5) apresentam o fenômeno através de uma visão sistêmica, destacando características que revelam a sua complexidade ao explorarem causas de diferentes naturezas e ao problematizarem seus efeitos. Nesse caso, as controvérsias científicas são apresentadas, principalmente, ao destacarem as discussões que envolvem as origens do fenômeno. Essas pesquisas também problematizam a ideia de que seja possível prever e descrever os comportamentos futuros do clima, uma vez que a probabilidade e a instabilidade do fenômeno dificultam a apresentação dessas previsões. 
Apesar de constatarmos a ideia de catástrofe, certeza e consenso associada às mudanças do clima, concluímos que esses pesquisadores apresentam informações importantes sobre o tema. Assim, não devemos levar em consideração apenas um único ponto de vista ou fator que interfira diretamente nas mudanças do clima e que as relações entre os diversos elementos que constituem o sistema climático nos presenteiam com um futuro incerto, imprevisível e irreversível.

Tendo em mente esse panorama acerca das compreensões apresentadas por pesquisas de EA sobre as mudanças climáticas, e considerando que esses trabalhos estão vinculados ao contexto escolar, entendemos que uma possível implicação desta pesquisa para estudos futuros seria a de investigar como as práticas escolares de EA têm apresentado a referida temática aos estudantes. Além disso, também seria relevante continuar esse estudo teórico, analisando, agora, as teses e dissertações de EA que versam sobre as mudanças climáticas e que foram produzidas na última década (2010-2020). 


\title{
The theme of climate change in brazilian thesis and dissertations on environmental education
}

\begin{abstract}
This paper presents some results related to a research with thesis and dissertations in the field of Environmental Education (EE). The aim of research was to identify aspects of the climate change theme highlighted in these studies. To delimit the documentary corpus, two EE doctoral thesis and 45 master's degree dissertations defended in the period from 1987 to 2010 were selected. All of them were found in the CAPES Thesis and Dissertations Database. The documentary corpus was formed with seventeen EE master's degree dissertations that explore the climate change. Based on some criteria, five surveys were submitted to content analysis. From the considerations on the theme of climate change present in these surveys, three categories were elaborated. These categories show us some understandings of the authors of these studies on the phenomenon causes, its consequences and the possible measures capable of mitigating its effects. Two master's degree dissertations bring considerations that use the term complexity to justify difficulties in choosing a single natural or anthropic cause related to the origins of climate change. They also highlight the scientific controversies related to climate change. Three master's degree dissertations present sensationalist positions in highlighting the climate change consequences, an aspect that is problematized by two other studies when emphasizing that the uncertainties related to a complex phenomenon make it difficult to present such forecasts. Finally, it is important to point some arguments presented in one specific master's degree dissertation that presented some considerations about mitigation measures for the phenomenon. They presented arguments related to economic and political controversies and that result from the debate about the adoption of such measures. In terms of conclusion, it is important to note that these researchers present some relevant information on the topic, an aspect that certainly can encourage the research area in EE to deepen the reflections on climate changes and to propose new research problems.
\end{abstract}

KEYWORDS: Climate changes. Environmental education. Controversy. 


\section{REFERÊNCIAS}

BARDIN, L. Análise de Conteúdo. Lisboa: Edições 70, 2010.

CAPES. Catálogo de Teses e dissertações. Disponível em:

http://bancodeteses.capes.gov.br. Acesso em: 05 mar. 2020.

CARVALHO, L. M. A Temática Ambiental e a Escola de 10 grau. 1989. 282 f. Tese (Doutorado em Educação) - Universidade de São Paulo, São Paulo, 1989.

CARVALHO, L.M. et al. A educação ambiental no Brasil: análise da produção acadêmica - teses e dissertações. CNPq: Relatório Científico. Rio Claro, UNESP Rio Claro, UNICAMP, USP - Ribeirão Preto, 2016.

CARVALHO, L. M.; CAVALARI, R. M. F.; SILVA, D. S. Ambientalização nas instituições de ensino superior: as teses e dissertações em Educação Ambiental desenvolvidas no Brasil. In: GUERRA, A. F. S. (Orgs.). Ambientalização e sustentabilidade nas universidades: subsídios, reflexões e aprendizagens. Itajaí: Editora da Univali, 2015. p. 47-63.

EARTE: estado da arte da pesquisa em Educação Ambiental no Brasil. Disponível em: http://www.earte.net. Acesso em: 10 abr. 2020.

FERREIRA, N. S. A. As Pesquisas denominadas "Estado da Arte". Educação \& Sociedade: Revista de Ciências da Educação, Campinas, Ano XXIII, n. 79, p. 257272, 2002. Disponível em: https://bit.ly/3cbSA6I. Acesso em: 15 mar. 2020.

FRACALANZA, H.; AMARAL, I. A.; MEGID NETO, J.; EBERLIN, T. S. A Educação Ambiental no Brasil: Panorama Inicial da produção Acadêmica. Ciências em Foco, Campinas, v. 1, n. 1, p. 1-14, 2008. Disponível em: https://bit.ly/2VnwWFk. Acesso em: 12 mar. 2020.

JACOBI, P. R.; GUERRA, A. F. S.; SULAIMAN, S. N.; NEPOMUCENO, T. Mudanças Climáticas Globais: a resposta da Educação. Revista Brasileira de Educação, Rio de Janeiro, v. 16, n. 46, p. 135-268, 2011. Disponível em: https://bit.ly/3b2Crjl. Acesso em: 12 mar. 2020.

KERR, A. S. Clima global, meio ambiente e justiça social. Le Monde Diplomatique Brasil, São Paulo, n. 54, p. 10-11, 2012. Disponível em: https://bit.ly/2RvO3DR. Acesso em: 20 mar. 2020.

LIMA, G. F. C. Mudanças climáticas e conservação social: riscos e alternativas ao aquecimento global. Gaia Scientia, João Pessoa, v. 3, n. 1, p. 35-46, 2009. Disponível em: https://bit.ly/3b6AYZq. Acesso em: 03 abr. 2020.

MORIN, E. Introdução ao pensamento complexo. 3 ed. Porto Alegre: Sulina, 2007.

OLIVEIRA, M.; VECCHIA, F. A controvérsia das mudanças climáticas e do 
Periódico Eletrônico Fórum ambiental da Alta Paulista, Tupã, v. 5, p. 946-962, 2009.

PAINEL INTERGOVERNAMENTAL SOBRE MUDANÇAS DO CLIMA (IPCC). Mudança do Clima 2007: A Base das Ciências Físicas. Contribuição do Grupo de Trabalho I ao Quarto Relatório de Avaliação do Painel Intergovernamental sobre Mudança do Clima. Disponível em: https://bit.ly/2Xj4Mw7. Acesso em: 13 mai. 2020.

PRIGOGINE, I. As leis do caos. São Paulo: Unesp, 2002.

REIS, P. R. Ciência e controvérsia. Revista de Estudos Universitários, Sorocaba, v. 35, n. 2, p. 9-15, 2009. Disponível em: https://bit.ly/34vJmyY. Acesso em: 14 mar. 2020.

REIS, D. A.; SILVA, L. F.; FIGUEIREDO, N. As complexidades inerentes ao tema mudanças climáticas: desafios e perspectivas para o Ensino de Física. Ensaio Pesquisa em Educação em Ciências, Belo Horizonte, v. 17, n. 3, p. 535-554, 2015. Disponivel em: https://bit.ly/2OLSIhV. Acesso em: 30 abr. 2020.

RINK, J. (2014). Ambientalização curricular na educação superior: tendências reveladas pela pesquisa acadêmica brasileira (1987-2009). 2014. 262 f. Tese (Doutorado em Educação) - Universidade Estadual de Campinas, Campinas, 2014.

UMA VERDADE Inconveniente. (An inconvenient truth). Documentário Dirigido por Davis Guggenheim. EUA: Paramount. 2006. 100 min. sonor. color.

UNITED Nations Framework Convention on Climate Change - UNFCCC. Kyoto Protocol to the United Nations Framework Convention on Climate Change. FCCC/CP/1997/L.7/Add.1. 10 dez. 1997. Disponível em: https://bit.ly/2WRh3ZD. Acesso em: 12 mai. 2020.

VEIGA, J. E.; VALE, P. M. Aquecimento global: um balanço das controvérsias. In: Brasil no Século XXI: Desafios do Futuro (Ciclo de seminários), 2007, São Paulo. Anais [...] São Paulo: USP, 2007. p. 1-52.

WATANABE-CARAMELLO, G. Aspectos da complexidade: contribuições da física para a compreensão do tema ambiental. 2012. 246 f. Tese (Doutorado em Ensino de Ciências) - Universidade de São Paulo, São Paulo, 2012.

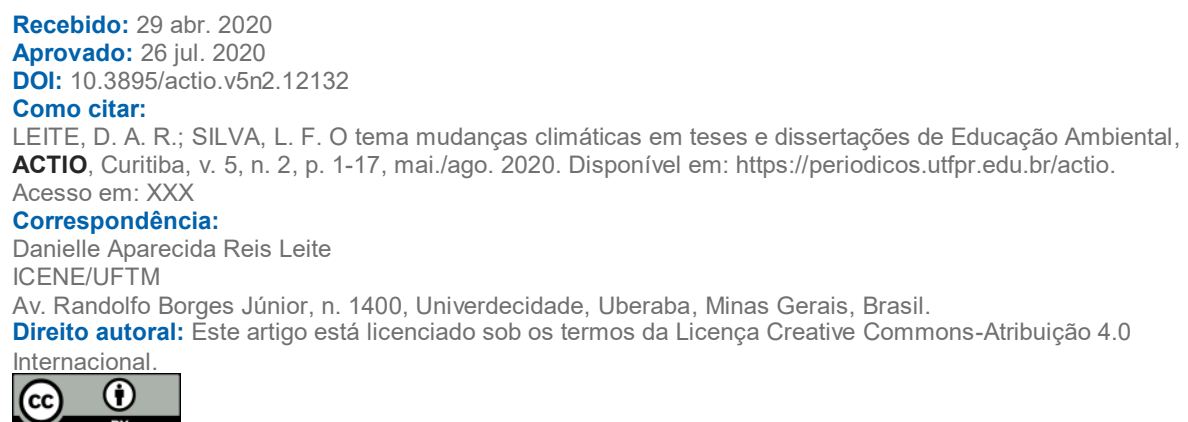

